\title{
Identification of a 16,600-Dalton Outer Membrane Protein on Nontypeable Haemophilus influenzae as a Target for Human Serum Bactericidal Antibody
}

Timothy F. Murphy," Linda C. Bartos," Peter A. Rice,‡ M. Bud Nelson," Kathleen C. Dudas," and Michael A. Apicella* *Division of Infectious Diseases, Department of Medicine, State University of New York at Buffalo School of Medicine, Buffalo, New York 14215; and $\ddagger$ The Maxwell Finland Laboratory for Infectious Diseases, Boston City Hospital, Boston University School of Medicine, Boston, Massachusetts 02118

\begin{abstract}
A 16,600-D outer membrane protein is present in all strains of Haemophilus influenzae and antibodies to this protein are present in human serum. This study was designed to assess the role of this outer membrane protein (P6) in nontypeable $H$. influenzae as a target for human serum bactericidal antibody. P6 was isolated and coupled to an affinity column. Depleting normal human serum of antibodies to P6 by affinity chromatography resulted in reduced bactericidal activity of that serum for nontypeable $\boldsymbol{H}$. influenzae. Immunopurified antibodies to P6 from human serum were bactericidal. Finally, preincubation of bacteria with a monoclonal antibody that recognizes a surface epitope on P6, inhibited human serum bactericidal killing. Taken together, these experiments establish that $\mathbf{P 6}$ is a target for human bactericidal antibodies. This observation provides evidence that P6 plays a potentially important role in human immunity to infection by nontypeable $\boldsymbol{H}$. influenzae.
\end{abstract}

\section{Introduction}

The incidence of infection due to nontypeable Haemophilus influenzae has been underestimated for years. Over the past five to seven years, a substantial body of literature has established that this bacterium is an important pathogen in both adults and children (1-6). Nontypeable $H$. influenzae is a major cause of respiratory infections in adults, particularly in chronic bronchitis $(1,6)$. It causes $\sim 20 \%$ of all episodes of acute otitis media in children (4). In addition, nontypeable $H$. influenzae causes a variety of other less common infections, such as meningitis, postpartum sepsis, neonatal sepsis, sinusitis, and others (1-3, 79). With the recognition of this bacterium as an important human pathogen, investigation has focused on understanding the pathogenesis of and immunity to infection, with an ultimate goal of prevention of these infections.

Since the presence of bactericidal antibodies in serum is related to protection from infection due to $H$. influenzae type b (10) and encapsulated meningococci (11), there has been interest in studying bactericidal antibody to nontypeable $H$. influenzae in human serum. Indeed, there is evidence that bactericidal antibody is related to protection from otitis media caused by the

Address reprint requests to Dr. Murphy at the Division of Infectious Diseases, Erie County Medical Center, 462 Grider Street, Buffalo, NY 14215. 1986.

Received for publication 17 March 1986 and in revised form 23 June

J. Clin. Invest.

(c) The American Society for Clinical Investigation, Inc.

0021-9738/86/10/1020/08 $\$ 1.00$

Volume 78, October 1986, 1020-1027 bacterium. Shurin et al. (12) demonstrated that the absence of bactericidal antibody to a strain of nontypeable $H$. influenzae in the sera of children is associated with susceptibility to otitis media due to nontypeable $H$. influenzae. Identifying surface structures that are targets of human bactericidal antibody is important in understanding human immunity and could direct efforts in vaccine development.

Previous work from our laboratory has identified a 16,600 D outer membrane protein (OMP) ${ }^{1}$ that contains an epitope present in all of 150 strains tested of $H$. influenzae, both typeable and nontypeable (13). Antibody to this OMP is present in human serum. The current study establishes that this 16,600-D OMP (P6) is a target of human bactericidal antibodies.

\section{Methods}

Bacterial strains. Nontypeable $H$. influenzae strains 3524 and 1479 were isolated from the sputum of two adults with chronic bronchitis at the Erie County Medical Center, Buffalo, NY. The identity of the species of the strains was confirmed by colonial morphology and growth requirement for hemin and nicotinamide adenine dinucleotide. The isolates were confirmed as nontypeable by counterimmunoelectrophoresis with use of reference strains and antiserum from the Centers for Disease Control (14). Strains were stored in Mueller-Hinton broth plus $10 \%$ glycerol at $-70^{\circ} \mathrm{C}$

Sources of antibodies. Pooled normal human serum (pNHS) was obtained from six healthy adults in Buffalo, NY. Two individual normal human serum samples were obtained from healthy adults in Buffalo (NHS-1) and Boston, MA (NHS-2). Neither of these was part of pNHS. Sera from Buffalo were heated at $56^{\circ} \mathrm{C}$ for $30 \mathrm{~min}$ to inactivate complement and stored in aliquots at $-20^{\circ} \mathrm{C}$. NHS-2 from Boston was stored at $-70^{\circ} \mathrm{C}$ and thawed just prior to use.

Mouse monoclonal antibody $7 \mathrm{~F} 3$ is an IgG3 immunoglobulin and recognizes an epitope on P6; this epitope is present in all strains of $H$. influenzae. Antibody 7F3 has been characterized in detail elsewhere (13). Monoclonal antibody 3D2 recognizes an epitope on lipid A of $H$. influenzae; it has been described elsewhere (15). Both 7F3 and 3D2 hybridomas were developed from mice immunized with strain 3524.

Isolation of P6. A modification of the method of Munson and Granoff (16) was used to isolate P6. Outer membrane complex that consists predominantly of OMPs and lipo-oligosaccharide (LOS) was first prepared $(17,18)$. The relative insolubility of $\mathrm{P6}$ in $1 \%$ sodium dodecyl sulfate (SDS), $0.1 \mathrm{M}$ Tris, $0.5 \mathrm{M} \mathrm{NaCl}, 0.1 \%$ beta mercaptoethanol, pH 8.0 (buffer B) was used to separate it from LOS and other OMPs.

Bacteria were grown on chocolate agar overnight at $37^{\circ} \mathrm{C}$ under $5 \%$ $\mathrm{CO}_{2}$. The bacteria were scraped from the plates and suspended in EDTA buffer (0.05 $\mathrm{M} \mathrm{Na}_{2} \mathrm{PO}_{4} ; 0.15 \mathrm{M} \mathrm{NaCl} ; 0.01 \mathrm{M}$ EDTA, pH 7.4). This suspension was incubated at $56^{\circ} \mathrm{C}$ for $30 \mathrm{~min}$. Cells were then disrupted by sonication on ice with five 15 -s periods of sonication at $100 \mathrm{~W}$. Un-

1. Abbreviations used in this paper: CFU, colony-forming units; K-ELISA, kinetic enzyme-linked immunosorbent assay; LOS, lipo-oligosaccharide; NHS, normal human serum; OMP, outer membrane protein; P6, 16,600D outer membrane protein; PAGE, polyacrylamide gel electrophoresis. 
broken cells and debris were removed by centrifugation at $10,000 \mathrm{~g}$ for $20 \mathrm{~min}$ at $4^{\circ} \mathrm{C}$. The supernatant was saved, and the resulting pellet was suspended in EDTA buffer and sonicated as described above. Unbroken cells and debris were again removed by centrifugation at $10,000 \mathrm{~g}$ for $20 \mathrm{~min}$ at $4^{\circ} \mathrm{C}$. The supernatants were pooled and centrifuged at 80,000 $g$ for $2 \mathrm{~h}$ at $4^{\circ} \mathrm{C}$. The clear, gel-like pellets were suspended in distilled water and lyophilized. The resulting powder is referred to as outer membrane complex, which consists of OMPs and $\operatorname{LOS}(17,18)$.

To separate P6, outer membrane complex was suspended in buffer B $(0.5 \mathrm{mg} / \mathrm{ml})$ and incubated at $37^{\circ} \mathrm{C}$ for $30 \mathrm{~min}$. The insoluble material was removed by centrifugation at $100,000 \mathrm{~g}$ for $60 \mathrm{~min}$ at $37^{\circ} \mathrm{C}$. The pellet was resuspended, incubated, and centrifuged in the same way two more times. The pellets, which contained P6, were subjected to SDSpolyacrylamide gel electrophoresis (PAGE) and Western blot analysis.

To solubilize $\mathbf{P} 6$, the pellets were suspended in buffer $\mathrm{B}$, incubated at $60^{\circ} \mathrm{C}$ for $30 \mathrm{~min}$ and centrifuged at $100,000 \mathrm{~g}$ for $60 \mathrm{~min}$ at $37^{\circ} \mathrm{C}$. The protein concentration in the supernatant (which contained P6), was determined by measurement of the optical density at $280 \mathrm{~nm}\left(\mathrm{OD}_{280}\right)$ using a standard curve with bovine serum albumin (BSA) in buffer B. For each measurement a new standard curve was constructed using BSA at $0.125,0.25,0.50,1.0$, and $2.0 \mathrm{mg} / \mathrm{ml}$. These consistently yielded a linear curve and showed minimal day-to-day variability. Measurements of the protein concentration of the same P6 solution on different days were highly reproducible. Each $100 \mathrm{mg}$ (dry weight) of outer membrane complex yielded $\sim 1 \mathrm{mg}$ (by $\mathrm{OD}_{280}$ ) of $\mathrm{P} 6$.

SDS-PAGE. P6 and whole cell preparations were subjected to SDSPAGE with $13.2 \%$ separating gels. Preparations were heated at $100^{\circ} \mathrm{C}$ for $5 \mathrm{~min}$ in sample buffer containing $0.06 \mathrm{M}$ Tris, 1.2\% SDS, 1 or $5 \%$ beta mercaptoethanol, $11.9 \%$ glycerol, and $0.003 \%$ bromophenol blue. Gels were subjected to Coomassie Blue stain (14), silver stain (17), or Western blot assay.

Western blot assay. Gels were placed with a nitrocellulose sheet that had been previously boiled in distilled water and immersed in $0.3 \mathrm{M}$ sodium citrate plus $3 \mathrm{M} \mathrm{NaCl}$. Electrophoretic transfer was carried out in an electrophoresis unit (Transphor, Hoefer Scientific Instruments, San Francisco, CA) at $50 \mathrm{~V}$ for $90 \mathrm{~min}$. The electrode buffer was 0.025 M Tris, pH 8.3, $0.192 \mathrm{M}$ glycine, and 20\% methanol. After transfer, the nitrocellulose sheet was placed in $3 \%$ gelatin in buffer $\mathrm{A}(0.01 \mathrm{M}$ Tris, $0.15 \mathrm{M} \mathrm{NaCl}, \mathrm{pH} 7.4$ ) for $30 \mathrm{~min}$. After the sheet was rinsed with buffer $A$, it was incubated in appropriate dilutions of serum, serum fraction, or monoclonal antibody overnight at room temperature. The sheet was rinsed with buffer $A$ and placed in a 1:3,000 dilution of peroxidase conjugate and shaken for $1 \mathrm{~h}$ at room temperature. In some experiments phosphate-buffered saline (PBS) plus $0.1 \%$ tween 20 was used in place of buffer $\mathrm{A}$. The sheet was rinsed and immersed in horseradish peroxidase color development solution $\left(0.015 \% \mathrm{H}_{2} \mathrm{O}_{2}\right.$; Bio-Rad Laboratories, Richmond, CA) for $45 \mathrm{~min}$.

Kinetic enzyme-linked immunosorbent assay (K-ELISA). K-ELISA were performed to quantitate human serum antibody to P6 $(17,19)$. Ultraviolet disposable polystyrene cuvettes (Fisher Scientific Co., Pittsburgh, PA) were washed with ethanol and dried. 1-ml vol were used for all steps. Cuvettes were coated with $1 \mu \mathrm{g} / \mathrm{ml}$ of solubilized P6 that had been stored at $-20^{\circ} \mathrm{C}$ and heated to $60^{\circ} \mathrm{C}$ each time before coating to assure optimal solubility. P6 was incubated in the cuvette in sensitization buffer ( $0.05 \mathrm{M}$ Tris; $0.002 \mathrm{M}$ EDTA; $0.3 \mathrm{M} \mathrm{KCl}, \mathrm{pH} 8.0)$ at $37^{\circ} \mathrm{C}$ overnight. The cuvettes were then washed three times with $0.3 \%$ Tween 20 in PBS (PBS-tween) and dilutions of serum or serum fractions were added to cuvettes. The sera were incubated for $1 \mathrm{~h}$ at $37^{\circ} \mathrm{C}$. After washing, a 1:3,000 dilution of conjugate (protein A peroxidase; Zymed Laboratories, San Francisco, CA, or peroxidase-goat anti human IgM; Kirkegaard and Perry Laboratories, Inc., Gaithersburg, MD) in PBS-tween was added and incubated for $1 \mathrm{~h}$ at $37^{\circ} \mathrm{C}$. Each cuvette was then washed and placed in a spectrophotometer (Varian 634, Varian Associates, Palo Alto, CA) with the analogue output connected through an A-D converter to an Apple Ile computer (Apple Computer, Cupertino, CA), which was programmed to calculate the rate of change per minute of absorbance at $460 \mathrm{~nm}$. A 1-ml amount of substrate was added to the cuvette, the $\mathrm{OD}_{460}$ was measured for $3 \mathrm{~min}$, and the change in $\mathrm{OD}_{460}$ per minute was cal- culated. The substrate was prepared by dissolving $10 \mathrm{mg}$ of $O$-dianisidine $\cdot 2 \mathrm{HCl}$ (Sigma Chemical Co., St. Louis, MO) in $1 \mathrm{ml}$ of methanol plus $1 \mathrm{ml}$ of substrate buffer $\left(0.05 \mathrm{M} \mathrm{NaHCO}_{3}\right.$ adjusted to $\mathrm{pH} 5.0$ with glacial acetic acid). $1.67 \mathrm{ml}$ of this was then added to $0.1 \mathrm{ml}$ of $3 \% \mathrm{H}_{2} \mathrm{O}_{2}$ and substrate buffer was added to a final $100-\mathrm{ml}$ vol.

Controls were run with each set of K-ELISAs. A cuvette for each conjugate was "coated" with sensitization buffer only (no antigen), followed by serum, conjugate, and substrate as described above. In the other set of controls, PBS-tween was used in place of serum (no antibody) and the other steps were performed as described. These controls consistently showed little or no background. K-ELISAs were performed in duplicate and the mean of the two values was calculated.

Affinity chromatography. P6 was coupled to an affinity column. Solubilized P6 was isolated as described above and SDS was partially removed from the preparation using Extracti-Gel D (Pierce Chemical Co., Rockford, IL), equilibrated with buffer B that was lacking SDS. The protein was then promptly dialyzed overnight against coupling buffer $\left(0.1 \mathrm{M} \mathrm{NaHCO}_{3}, 0.5 \mathrm{M} \mathrm{NaCl}, 0.5 \%\right.$ Zwittergent, $\mathrm{pH}$ 8.3). $1 \mathrm{~g}$ of cyanogen bromide-activated Sepharose 4B (Pharmacia Fine Chemicals, Piscataway, $\mathrm{NJ}$ ) was swelled with $1 \mathrm{mM} \mathrm{HCl}$ in a sintered glass funnel. After washing once with coupling buffer, the gel was transferred to a flask containing $4 \mathrm{mg}$ of P6 in $8 \mathrm{ml}$ of coupling buffer. This was shaken at room temperature for $2 \mathrm{~h}$. The slurry was placed back in the sintered glass funnel and the liquid was aspirated. The protein content in this liquid was 2 $\mathrm{mg}$ indicating that $\sim 2 \mathrm{mg}$ of $\mathrm{P} 6$ was coupled on to the column. The gel was washed and then shaken overnight at $4^{\circ} \mathrm{C}$ in $0.2 \mathrm{M}$ glycine, $\mathrm{pH} 8.0$ to block remaining active groups. Excess adsorbed protein was washed away with coupling buffer alternating with $0.1 \mathrm{M}$ sodium acetate, $0.5 \mathrm{M}$ $\mathrm{NaCl}, \mathrm{pH}$ 4.0. The gel was placed in a column and equilibrated with PBS. This is referred to as the P6 column. A second column was made simultaneously in which coupling buffer was used in place of P6 in coupling buffer. All other manipulations were identical to those of the P6 column. This second column is referred to as the control column.

To deplete human serum of antibody to $P 6,4 \mathrm{ml}$ of a 1:5 dilution in PBS of serum was applied to the affinity columns. All effluent fractions were collected until $\mathrm{OD}_{280}$ measurements were no longer detected. These fractions were pooled, dialyzed against Gey's balanced salt solution and concentrated to $2 \mathrm{ml}$ by pressure filtration. These effluents from both the P6 and control columns were subjected to Western blot assay, KELISA, and bactericidal assay.

To immunopurify human serum antibody to $P 6,40 \mathrm{ml}$ of a $1: 5$ dilution in PBS of pNHS was run over the affinity column over $\sim 3 \mathrm{~h}$. After washing the columns with $100 \mathrm{ml}$ of PBS, the immunoadsorbed antibody was eluted with $1 \mathrm{ml}$ of $0.2 \mathrm{M}$ glycine, $\mathrm{pH} 2.5$. The affinity column was coupled in tandem with a Biogel P-30 desalting column equilibrated with PBS to remove glycine. 1-ml fractions were collected and the $\mathrm{OD}_{280}$ was monitored. No protein peak was detected by $\mathrm{OD}_{280}$ measurements (sensitivity $\sim 20 \mu \mathrm{g} / \mathrm{ml}$ ). When performing affinity chromatography using this method in other systems, immunoglubulin elutes in fractions 4 through 9. Therefore, these fractions were pooled and dialyzed against Gey's balanced salt solution. This is referred to as eluate. For each serum sample subjected to affinity chromatography on the P6 column, the identical method was performed with the control column. Eluates from both columns were tested in bactericidal assay, Western blot assay, and K-ELISA.

\section{Bactericidal Assay}

REAGENTS. Nontypeable H. influenzae. Strain 3524 was grown to midlogarithmic phase in freshly prepared brain heart infusion broth supplemented with hemin $(10 \mu \mathrm{g} / \mathrm{ml})$ and nicotinamide adenine dinocleotide $(10 \mu \mathrm{g} / \mathrm{ml})$. An aliquot was diluted to $5 \times 10^{4}$ colony-forming units (CFU) per $\mathrm{ml}$ in $10 \% \mathrm{BSA}$ in Gey's balanced salt solution. A 42- $\mu$ l amount of this dilution was used in a total reaction volume of $250 \mu \mathrm{l}$. Therefore, $\sim 2,000$ CFU were present in the reaction mixture in each bactericidal assay.

Complement. Blood from two young adults with combined immunodeficiency syndrome was allowed to clot at room temperature for 15 min. The serum was separated by centrifugation, filter sterilized, and 
frozen at $-70^{\circ} \mathrm{C}$ in aliquots. Each vial was thawed and used only once. Blood was obtained from these individuals on three separate occasions. The total hemolytic complement activity of the sera after thawing was 44,50 , and $47 \mathrm{CH}_{50} \mathrm{U} / \mathrm{ml}$ (normal 25 to 51) from the three batches. A final complement concentration of $8.8 \%$ was used in each reaction mixture. The complement sources repeatedly caused no killing of strain 3524 at this concentration.

Antibodies. As noted, pNHS and NHS-1 were heated at $56^{\circ} \mathrm{C}$ for 30 min to inactivate complement so that each reaction mixture had the same amount of complement. Sera and serum fractions were assayed in varying amounts. The remainder of the $250-\mu$ l total reaction mixture was made up with Gey's balanced salt solution.

METHOD. Reagents were added to the tube with complement added last. The tubes were incubated at $37^{\circ} \mathrm{C}$ with shaking for $2 \mathrm{~h}$. Colony counts were performed at time $0,30,60$, and $120 \mathrm{~min}$ by plating aliquots of $25 \mu \mathrm{l}$ onto chocolate agar plates in duplicate. The plates were incubated at $37^{\circ} \mathrm{C}$ in $5 \% \mathrm{CO}_{2}$ overnight and the colonies on each plate were counted. There were approximately 200 to 300 colonies on each plate at time 0 . Both a negative and positive control were included in each experiment. The negative control consisted of complement source and bacteria with no added antibody to assure that the organisms maintained their viability and that the complement source was not killing. The positive control consisted of heat-inactivated serum, complement source, and bacteria to assure that complement was active. In addition, for each serum fraction from the P6 column, the analogous fractions from the control column were assayed such that the same log phase bacteria were tested concurrently with fractions from the two columns.

All aliquots from bactericidal assays were plated in duplicate and the mean of the two values was calculated. Analysis of 25 assays representing 148 plates with over $100 \mathrm{CFU}$ per plate indicate that the standard deviation from the mean was 3 per $100 \mathrm{CFU}$ per duplicate set. The results presented represent the mean of the duplicate values and the confidence bars in the figures represent the percent survival calculated for each of the duplicate values individually.

Inhibition of bactericidal antibody by monoclonal antibody $7 F 3$. Mouse ascites fluid containing antibody $7 \mathrm{~F} 3$ or $3 \mathrm{D} 2$ were purified by affinity chromatography over a column to which protein A was coupled. Antibody was eluted with $0.2 \mathrm{M}$ glycine, ( $\mathrm{pH} 2.5$ ) and glycine was removed with a P30 column equilibrated with PBS. Inhibition of bactericidal activity was measured by employing methods similar to those described above, except that bacteria were preincubated with dilutions of 7F3 or 3D2 for $15 \mathrm{~min}$ at room temperature before the addition of NHS- 2 and complement. An incubation period of $30 \mathrm{~min}$ was chosen for these assays based on experiments that showed $70 \%$ or greater killing of organisms during this period using serum diluted to near the endpoint of killing. Percent inhibition of killing by 7F3 and 3D2 was calculated as the difference in the numbers of organisms killed comparing the control reaction (NHS-2 above) with the test reaction (organisms preincubated with $7 F 3$ or 3D2) divided by the number killed in the control reaction alone. Each assay was performed in duplicate on two or three separate occasions and the results expressed as mean \pm range.

\section{Results}

Characterization of P6 preparation. P6 was isolated from strains 3524 and 1479 of nontypeable $H$. influenzae. Fig. 1 is an SDS gel stained with Coomassie Blue showing P6 isolated from strain 3524. The band shows faint staining with Coomassie Blue. In spite of this faint staining, however, transfer to nitrocellulose and detection with antibody $7 \mathrm{F3}$ or NHS consistently resulted in a prominent band. Fig. 2 is a Western blot assay in which a whole cell preparation and P6 preparation are tested with three antisera. It shows that P6 contains the 7F3 epitope (13) and that the preparation contains no detectable LOS using monoclonal antibody 3D2. Antibody 3D2 detects nanogram quantities of LOS in this assay $(15,17)$. In addition, LOS was not detected

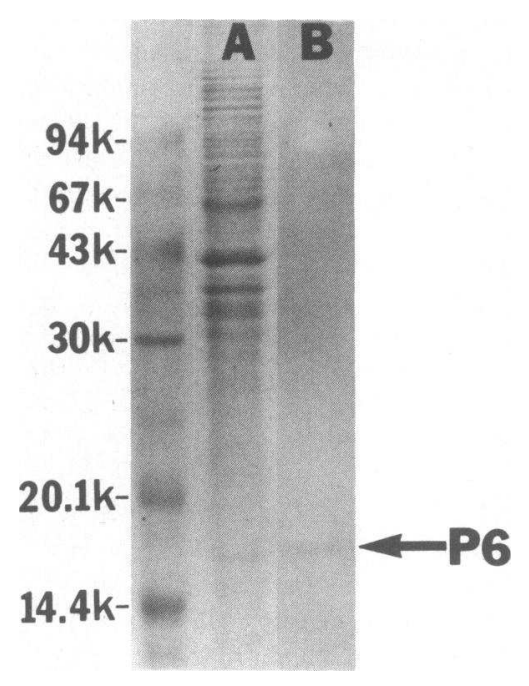

Figure 1. SDS-polyacrylamide gel stained with Coomassie Blue. Lane $A$ contains a whole cell preparation of strain 3524 and lane $B$ contains a P6 preparation from strain 3524 . The faintly staining P6 band is noted by the arrow. Molecular weight standards are noted in thousands on the left.

when the P6 preparation was subjected to SDS-PAGE and silver staining. Fig. 2 also shows that normal human serum contains antibody to P6 detected in both a whole cell preparation and in the isolated $\mathrm{P} 6$ preparation.

When some of the P6 preparations were initially tested, a 41,000-dalton band was detected in SDS-PAGE. This corresponds to the major OMP and its presence indicated incomplete solubilization of the OMP in buffer B. In these circumstances, the P6 was resuspended in buffer B, incubated, and centrifuged as described above one or two more times. This resulted in disappearance of the high molecular band as detected by Coomassie Blue stain of SDS gels. It is possible that P6 is contaminated with a small amount of other OMPs. These proteins are not detected by Coomassie Blue stain, however, indicating that, if present, these OMPs are present in very small quantities. In

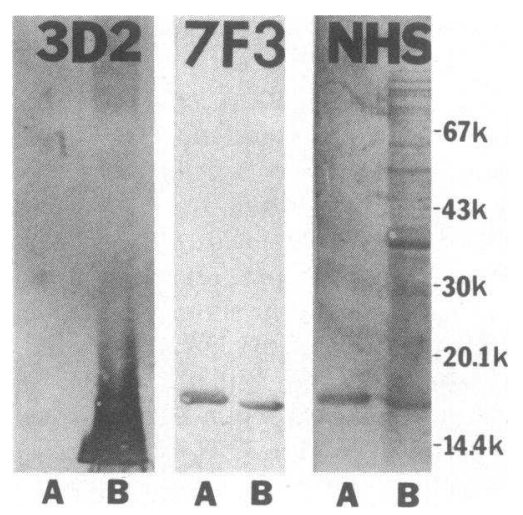

Figure 2. Western blot assay from a $13.2 \%$ gel. The $A$ lanes contain a P6 preparation from strain 3524 and the $B$ lanes contain a whole cell preparation of strain 3524 . The $3 D 2$ and $7 F 3$ lanes were incubated with 1:500 dilutions of mouse ascites fluid containing monoclonal antibodies 3D2 and 7F3, respectively. The $N H S$ lanes were incubated with a 1:250 dilution of NHS-1. All lanes were then treated with protein A-peroxidase and peroxide substrate. 
addition, NHS fails to detect the presence of any other OMPs in the P6 preparations in Western blot assay (Fig. 2).

When subjected to SDS-PAGE, the apparent molecular weight of P6 in the isolated preparation was slightly higher than the apparent molecular weight of P6 in the whole cell preparation. This is most obvious in Fig. 2. This difference probably results from some alteration of the protein during the isolation procedure.

Analysis of NHS depleted of antibody to P6. pNHS and NHS1 were subjected to affinity chromatography over the P6 and control columns. Effluents from the two columns were studied in Western blot assay in equivalent dilutions to determine whether the P6 column specifically depleted the NHS samples of antibody to P6. Fig. 3 shows that the P6 column removed antibodies to P6 from human serum and the control column did not remove antibodies to $\mathrm{P} 6$. In addition, antibodies to other proteins were present in the effluents indicating that the P6 column specifically depleted serum of antibodies to P6. The bands in lanes $A$ through $D$ of Fig. 3 were detected using protein Aperoxidase conjugate. Anti human IgM-peroxidase failed to detect antibody to P6 in whole pNHS and NHS-1 by Western blot assay.

K-ELISAs were performed to quantitate the difference in antibody titer to P6 in the effluents from the two columns. Table I shows the results of these experiments with both NHS-1 and pNHS. Each assay was performed in duplicate. Results of duplicate values varied from one another by $\sim 5 \%$. Whole serum was assayed in K-ELISA for IgG and IgM antibodies to P6. Comparison of results of control column effluents with whole serum indicated that some nonspecific loss of antibody occurred during the manipulations of affinity chromatography. However, control column effluents contained significantly more antibody to P6 than did P6 column effluents (Table I). These data indicate that both IgG and IgM antibodies to P6 were depleted from the sera by subjecting them to affinity chromatography over the P6 column.

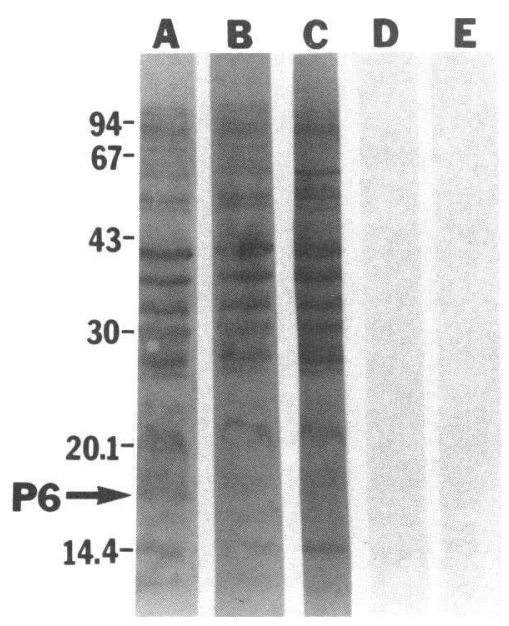

Figure 3. Western blot assays. All lanes contain a whole cell preparation of 3524. Lane $A$ was incubated with NHS-1 at a 1:250 dilution; lane $B$, control column effluent at 1:250; lane $C, \mathrm{P} 6$ column effluent at 1:250; lanes $D$ and $E, \mathrm{P} 6$ column eluate both at 1:2.5 dilution. Lanes $A$ through $D$ were then immersed in protein A-peroxidase and lane $E$ was immersed in anti-human IgM-peroxidase. These were followed by peroxide substrate. The P6 bands are noted by the arrow.
Table I. Measurement of Human Serum Antibody to P6 in Column Effluents and Eluates by Kinetic ELISA

\begin{tabular}{|c|c|c|c|c|}
\hline & \multicolumn{4}{|c|}{$\Delta \mathrm{OD}_{460}$ per minute $\times 1,000^{*}$} \\
\hline & \multicolumn{2}{|l|}{ IgG‡ } & \multicolumn{2}{|l|}{ IgM‡ } \\
\hline & $\begin{array}{l}\text { 1:25 } \\
\text { dilution§ }\end{array}$ & $\begin{array}{l}1: 50 \\
\text { dilution }\end{array}$ & $\begin{array}{l}1: 25 \\
\text { dilution }\end{array}$ & $\begin{array}{l}1: 50 \\
\text { dilution }\end{array}$ \\
\hline $\begin{array}{l}\text { Pooled NHS control } \\
\text { column effluent }\end{array}$ & 20.1 & 15.9 & 12.0 & 11.4 \\
\hline $\begin{array}{l}\text { Pooled NHS P6 } \\
\text { column effluent }\end{array}$ & 15.1 & 10.6 & 7.9 & 6.5 \\
\hline $\begin{array}{l}\text { NHS-1 control } \\
\text { column effluent" }\end{array}$ & 24.7 & 16.5 & 8.3 & 5.3 \\
\hline $\begin{array}{l}\text { NHS-1 P6 } \\
\text { column effluent } \$\end{array}$ & 13.5 & 10.9 & 0.7 & 1.0 \\
\hline & $\begin{array}{l}1: 2.5 \\
\text { dilutiont }\end{array}$ & $\begin{array}{l}1: 10 \\
\text { dilution }\end{array}$ & $\begin{array}{l}1: 2.5 \\
\text { dilution }\end{array}$ & $\begin{array}{l}1: 10 \\
\text { dilution }\end{array}$ \\
\hline Control column eluate & $0^{* *}$ & 0 & 0 & 0 \\
\hline P6 column eluate & 3.6 & 0 & 17.3 & 5.3 \\
\hline
\end{tabular}

* Results represent the mean of duplicate values.

¥ Protein A peroxidase was used to detect IgG and antihuman IgM peroxidase was used to detect IgM. Both were used at a dilution of 1:3,000.

$\S$ Effluents were assayed at dilutions of 1:25 and 1:50.

"NHS-1 is normal human serum from a healthy adult.

I Eluates were assayed at dilutions of 1:2.5 and 1:10.

** Negative values were recorded as zero. None of the values were below -2.5 .

Bactericidal assays were performed to determine whether depleting human serum of antibody to P6 resulted in a change in bactericidal activity of that serum. Bactericidal assays were initially performed with varying concentrations of whole NHS1 and pNHS to determine the minimum concentrations that demonstrated bactericidal activity. Effluents were assayed at these concentrations. This was done to ensure that excess bactericidal antibody was not present in the bactericidal reaction mixture so that the assay would detect a change in the amount of bactericidal antibody. For NHS- 1 a concentration of $15 \%$ serum was chosen and for pNHS, a concentration of $20 \%$ was chosen.

Fig. 4 shows the results of bactericidal assays for NHS-1 effluents tested at concentrations equivalent to $15 \%$ serum. At this concentration, P6 column effluent showed no bactericidal activity for strain 3524 , whereas the control column effluent had bactericidal activity similar to that of whole serum. Fig. 5 shows the results of bactericidal assays for pNHS column effluents assayed in concentrations equivalent to $20 \%$ serum. The P6 column effluent showed less bactericidal activity than the corresponding effluent from the control column. Therefore, depleting NHS- 1 and pNHS of antibody to P6 reduces bactericidal activity of the sera for strain 3524 .

Upon initial examination, Figs. 4 and 5 might appear to indicate that much or all of human serum bactericidal antibody is directed at P6. As noted above, however, these assays were performed with serum concentrations near the endpoint of bactericidal killing. If these sera were assayed at higher concentra- 


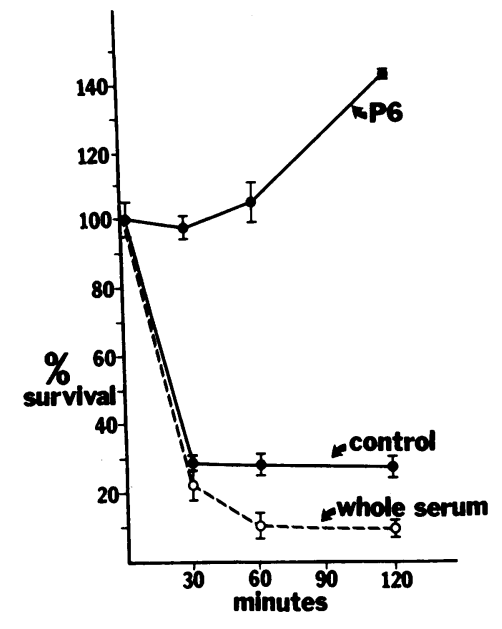

Figure 4. Results of bactericidal assay using column effluents of NHS-1. Effluents from the control and P6 columns were assayed at dilutions equivalent to $15 \%$. Whole serum (NHS-1) was assayed at $15 \%$. Each point represents the mean of duplicate values and the confidence bars represent the ranges.

tions, the difference between P6 and control effluents would be less striking due to the presence of higher concentrations of bactericidal antibody to other surface antigens.

Analysis of immunopurified antibody to P6. Antibody to P6 in eluates from the affinity columns was quantitated in K-ELISA. Table I shows that a substantial titer of IgM antibody to P6 was present in the P6 column eluate while none was detected in the control column eluate. Using protein A-peroxidase conjugate, a small amount of IgG antibody to P6 was detected in the P6 column eluate. The eluates were subjected to Western blot assay using whole cell preparations. No antibody to P6 or other antigens was detected by Western blot with protein A-peroxidase or anti-human IgM peroxidase (Fig. 3).

Fig. 6 illustrates the results of bactericidal assays using immunopurified antibody to P6 as the source of antibody. When used at a concentration of $75 \%$, P6 column eluate produced $90 \%$ killing in $2 \mathrm{~h}$. None of the eluates from the control column demonstrated bactericidal activity when assayed concomitantly using the identical method. Results of control experiments indicate that killing was antibody directed and complement mediated. First, control column eluate that contained no detectable antibody to P6, but was otherwise identical to the P6 eluate showed no killing. Second, controls containing organisms, complement, and diluent with no added antibody produced no killing. Third, controls containing organisms, 75\% P6 eluate and diluent with no added complement produced no killing.

Inhibition of human bactericidal antibody by monoclonal antibody 7F3. We attempted to inhibit serum killing of 3524 with monoclonal antibodies $7 \mathrm{~F} 3$ and $3 \mathrm{D} 2$ in order to $(a)$ confirm

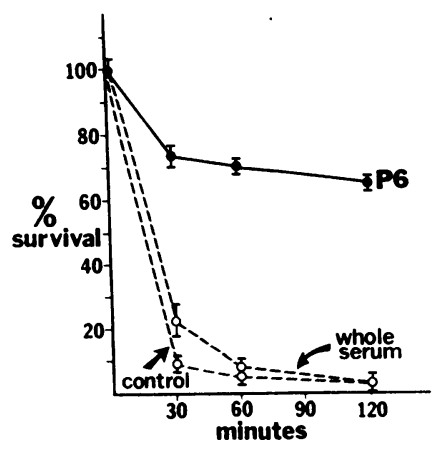

Figure 5. Results of bactericidal assay using column effluents of pNHS. Effluents from the control and P6 columns were assayed at dilutions equivalent to $20 \%$. Whole serum (pNHS) was assayed at $20 \%$. Each point represents the mean of duplicate values and the confidence bars represent the ranges.

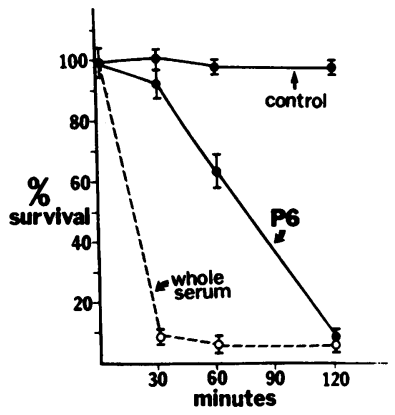

Figure 6. Results of bactericidal assay using column eluates of pNHS. The curve marked "P6" represents eluate from the P6 column, which comprised $75 \%$ of the bactericidal reaction mixture. The curve marked "control" represents an assay that contains complement but no antibody. The curve marked whole serum represents pNHS assayed at $20 \%$. Each point represents the mean of duplicate values and the confidence bars represent the ranges.

that P6 is a surface-exposed outer membrane antigen, $(b)$ to assess if P6 might serve as an acceptor site in situ for human bactericidal antibody, and $(c)$ to ascertain if inhibition by monoclonal antibody was specific or possibly the result of steric inhibition due to screening of nearby bactericidal antibody targets.

Fig. 7 shows the results of bactericidal inhibition assays in which strain 3524 was preincubated with dilutions of protein A purified monoclonal antibodies 7F3 and 3D2 before the addition of NHS- 2 and complement to the reaction mixtures. These experiments demonstrated that preincubation of bacteria with 7F3 inhibited human serum bactericidal killing while preincubation with antibody 3D2 had no effect on killing.

\section{Discussion}

This study establishes that P6, a 16,600-D OMP on nontypeable $H$. influenzae is a target for human bactericidal antibody. This observation is based on three sets of experiments $(a)$ In carefully controlled conditions, depleting normal human serum of antibody to P6 results in reduced bactericidal activity of serum for nontypeable $H$. influenzae. (b) Immunopurified antibody to P6 from human serum is bactericidal. (c) Monoclonal antibody 7F3,

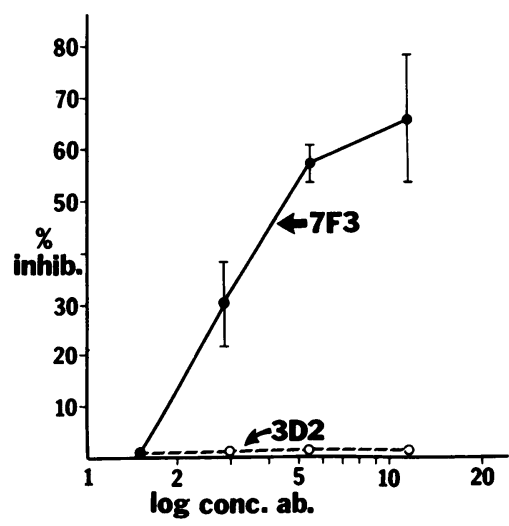

Figure 7. Inhibition of human serum bactericidal antibody by monoclonal antibodies. Bacteria were preincubated with dilutions of protein A purified monoclonal antibody. The $x$-axis shows the logarithm of the concentration of antibody inhibitor $(\mu \mathrm{g} / \mathrm{ml})$ and the $y$-axis shows the percent inhibition of bactericidal activity of NHS-2. Each point represents the mean of duplicate values and the confidence bars represent the ranges. 
which recognizes an epitope on P6 inhibits bactericidal activity of human serum for nontypeable $H$. influenzae. Taken together, these observations indicate that P6 is a human bactericidal locus.

Antibody to P6 in affinity column effluents and eluates were quantitated using a K-ELISA system (Table I). A K-ELISA was chosen because it offers advantages over conventional endpoint ELISA. First, K-ELISA is based on enzyme rate kinetics and yields quantitative linear data on antigen or antibody concentration. When antigen is present in excess, the results of K-ELISA are linear with regard to antibody concentration (19). In endpoint ELISA, enzyme concentration is linear with respect to activity only during the brief initial phase of the reaction and then only when the enzyme concentration is lower than that of substrate (19). A second advantage of K-ELISA is that background activity is minimal. In the experiments described here, control cuvettes consistently showed little or no activity. Finally, in our hands, K-ELISA shows better day-to-day reproducibility than endpoint ELISA. We have shown previously that the assay yields highly reproducible results when measuring antibody to outer membrane antigens of nontypeable $H$. influenzae in rabbit antisera (17) and mouse monoclonal antibodies (19). The results of assays in the present study indicate that K-ELISA is a reliable method for quantitating antibody to P6 in human serum as well.

Analysis of column effluents by K-ELISA and Western blot assay indicated that the P6 column depleted serum of both IgG and IgM antibody to P6 compared to the control column. However, analysis of column eluates indicated that very little IgG antibody was eluted from the column. Protein A-peroxidase did not detect antibody to $\mathrm{P} 6$ or other antigens in the P6 column eluates in Western blot assays in spite of clear-cut evidence of depletion of antibody to P6 by the P6 column (Fig. 3 and Table I). A possible explanation for this observation is that IgG antibody to P6 remained bound to the column and could not be eluted. An alternative explanation is that the eluting conditions denatured the IgG antibody so that it lost its activity.

Results of K-ELISA suggest that the antibodies to P6 in the P6 column eluates are predominantly IgM (Table I). These antibodies are detected by K-ELISA but not by Western blot assay. The inability of Western blot assay to detect IgM antibody in the P6 column eluate is consistent with the observation that IgM antibody to P6 is not detected in whole serum in Western blot assay. A possible explanation for this is that human IgM antibody to P6 does not bind well on nitrocellulose. An alternative explanation is that the determinants on P6 to which human IgM antibodies bind are not exposed when the protein is immobilized on nitrocellulose.

The possibility that small amounts of contaminating bactericidal antibodies to antigens other than P6 were bound to and eluted from the P6 column exists. However, this possibility is unlikely. In addition, the inhibition of human bactericidal antibody by antibody 7F3 represents an independent line of evidence that does not depend on fractionation of serum antibodies by affinity chromatography.

In the experiments involving inhibition of human bactericidal antibody 7F3 inhibits bacterial killing by binding to the epitope on P6. These experiments confirm that P6 antigen is surface exposed and that it may be a target, in situ for human bactericidal antibody.

Experiments were performed to determine if the addition of purified P6 antigen to bactericidal reaction mixtures would inhibit human bactericidal killing by immunoabsorbing P6 directed antibody, thereby making it unavailable for killing. Con- trol assays were performed in which buffer B without P6 was added in equivalent amounts to the reaction mixtures. Bactericidal activity of human serum was reduced in both P6 and control tubes. It appeared that the buffer B was interfering with complement-mediated bactericidal killing of the organisms. Various manipulations were attempted to assess whether P6 inhibited bactericidal killing using this method but control experiments indicated that the buffers necessary to keep P6 in solution interfered with the assay. The relative insolubility of P6 is exploited in isolating the protein but this property also resulted in an inability to perform bactericidal assays using P6 as an inhibitor in the soluble phase. For this reason, solid-phase immunoabsorption methods were pursued to demonstrate that P6 is a target for human bactericidal antibody.

It is of interest that an OMP is a target for human bactericidal antibody. Several studies have identified LOS and polysaccharide capsule as bactericidal loci in other nonenteric gram-negative bacteria such as Neisseria gonorrhoeae, $N$. Meningitidis and $H$. influenzae type b (20-23). However, recent studies of nontypeable $H$. influenzae have identified OMPs as surface structures recognized by bactericidal antibody and as potentially important in protection. Gnehm et al. (18) demonstrated that OMPs inhibit human bactericidal killing of nontypeable $H$. influenzae and that LOS from the same strain shows no inhibition. In addition, depleting human serum of antibody to OMPs reduced bactericidal activity of that serum. They used OMP preparations that contained multiple OMPs but the individual proteins recognized by human antibody were not identified. This study confirms that an OMP can act as a human bactericidal locus and identifies a specific OMP as such a target.

Other data suggest that antibody to OMPs are potentially important in protection from nontypeable $H$. influenzae infection. Karasic et al. (24) have adapted the use of a chinchilla model of otitis media to studies of nontypeable $H$. influenzae and susceptibility to reinfection caused by the organism. A tenfold rise in titer to OMPs was noted in all animals with their initial infection but most animals exhibited a minimal serologic response to LOS. Animals were completely protected against reinfection by the homologous strain. This study suggests that antibody to OMPs of nontypeable $H$. influenzae are protective in this animal model.

The identification of P6 as a bactericidal target in nontypeable strains might have implications in understanding human immunity to $H$. influenzae type b. Anticapsular antibody is an important determinant of protection from infection due to $H$. influenzae type b (25-27). Recently, however, several lines of evidence indicate that protection from infection does not correlate simply with antibody to capsule. Immunity appears to result from a more complex interplay of a number of factors, including antibody to somatic antigens. Several studies involving experimental models of $H$. influenzae type $\mathrm{b}$ infections have shown that antibody to OMPs can be protective (28-30). Indeed, Munson and Granoff (16) demonstrated that antibody to P6 is protective in their infant rat model. In addition, studies in humans provide evidence that antibodies to noncapsular antigens participate in human immunity to $H$. influenzae type b infections $(22,31,32)$. Future study will address whether P6 is a human bactericidal target for type b strains as well as nontypeable strains. This would have potential importance in vaccine development since proteins are more likely than polysaccharides to be immunogenic in infants, the population at highest risk for $H$. influenzae type $\mathrm{b}$ infection. 
The presence of P6 in the outer membrane of $H$. influenzae has been noted by several groups of investigators and has been the subject of recent investigation $(13,14,16,33,34)$. It makes up a relatively small proportion of the total protein content of the outer membrane. Munson and Granoff estimated by weight that the P6-peptidoglycan fraction made up 5\% of the outer membrane (16). Solubilized P6, apparently free of peptidoglycan comprised $\sim 1 \%$ of the outer membrane in this study. This may be an underestimation because P6 is not completely insoluble in $1 \%$ SDS buffer at $37^{\circ} \mathrm{C}$ since a band at $16,600 \mathrm{D}$ is visible when the $1 \%$ SDS buffer-soluble fraction is subjected to SDSPAGE. P6 appears to stain weakly with Coomassie Blue. SDSgels that show a rather faintly staining band with Coomassie Blue show a prominent band in Western blot assay with human serum or monoclonal antibody $7 F 3$. A portion of the OMP is exposed on the surface of the bacterium since P6 is accessible to bactericidal antibody, monoclonal antibody 7F3 and rabbit antisera stain the organism by immunofluorescence, and absorbed antiserum immunoprecipitates $\mathrm{P} 6$ from whole organisms (16). P6 contains an epitope common to all strains of $H$. influenzae tested thus far; this epitope is a highly specific marker for $H$. influenzae since the epitope is absent in virtually all other bacterial species tested (13). Antibody to P6 is present in human serum as demonstrated in Western blot assay and K-ELISA. It is worthy of note that the band is among the most prominent recognized by antibody in human serum in Western blot assay despite the relatively small amount of the protein in the outer membrane. Future studies will be directed at determining the function of the OMP, studying the antigenic heterogeneity or conservation of this OMP among strains, identifying the relevant epitopes on the protein, and determining whether P6 is a human bactericidal locus in type b strains. This will lead to further elucidation of the role of P6 in human immunity to infection caused by $H$. influenzae.

\section{Acknowledgments}

We thank Phyllis Rosenberg for secretarial assistance, Marlene Shero for photographic work, and Dr. Mark Wilson for providing immunoglobulin-deficient serum.

This work was supported by research grant AI 19641 from the National Institutes of Health.

\section{References}

1. Murphy, T. F., and M. A. Apicella. 1986. Nontypable Haemophilus influenzae: a review of clinical aspects, surface antigens and the human immune response to infection. Rev. Infect. Dis. In press.

2. Wallace, R. J., Jr., D. M. Musher, E. J. Septimus, J. E. McGowan, F. J. Quinones, K. Wiss, P. H. Vance, and P. A. Trier. 1981. Haemophilus influenzae infections in adults: characterization of strains by serotypes, biotypes and beta lactamase production. J. Infect. Dis. 144:101-106.

3. Wallace, R. J., Jr., C. J. Baker, F. J. Quinones, D. G. Hollis, R. E. Weaver, and K. Wiss. 1983. Nontypable Haemophilus influenzae (Biotype 4) as a neonatal, maternal, and genital pathogen. Rev. Infect. Dis. 5:123-135.

4. Bluestone, C. D., and J. O. Klein. 1983. Otitis media with effusion, atelectasis and eustachian tube dysfunction. In Pediatric Otolaryngology. C. D. Bluestone and S. E. Stool, editors. W. B. Saunders, Co., Philadelphia. $356 \mathrm{pp}$.

5. Berk, S. L., S. A. Holtsclaw, S. L. Wiener, and J. K. Smith. 1982. Nontypeable Haemophilus influenzae in the elderly. Arch. Intern. Med. 142:537-539.
6. Musher, D. M., K. R. Kubitschek, J. Crennan, and R. E. Baughn. 1983. Pneumonia and acute febrile tracheobronchitis due to Haemophilus influenzae. Ann. Intern. Med. 99:444-450.

7. Spagnuolo, P. J., J. J. Ellner, P. I. Lerner, M. C. McHenry, F. Flatauer, P. Rosenberg, and M. S. Rosenthal. 1982. Haemophilus influenzae meningitis: the spectrum of disease in adults. Medicine. 61:7485.

8. Evans, F. O., J. B. Sydnor, W. E. C. Moore, G. R. Moore, J. L. Manwaring, A. H. Brill, R. T. Jackson, S. Hanna, J. S. Skaar, L. V. Holdeman, G. S. Fitz-Hugh, M. A. Sande, and J. M. Gwaltney. 1975. Sinusitis of the maxillary antrum. N. Engl. J. Med. 293:735-739.

9. Wald, E. R., G. J. Milmoe, A. D. Bowen, J. Ledesma-Medina, N. Salamon, and C. D. Bluestone. 1981. Acute maxillary sinusitis in children. N. Engl. J. Med. 304:749-754.

10. Fothergill, L. D., and J. Wright. 1933. Influenzal meningitis. The relation of age incidence to the bactericidal power of blood against the causal organism. J. Immunol. 24:273-284.

11. Goldschneider, I., E. C. Gotschlich, and M. S. Artenstein. 1969. Human immunity to the meningococcus. I. The role of humoral antibodies. J. Exp. Med. 129:1307-1326.

12. Shurin, P. A., S. I. Pelton, I. B. Tager, and D. L. Kasper. 1980. Bactericidal antibody and susceptibility to otitis media caused by nontypable strains of Haemophilus influenzae. J. Pediatr. 97:364-369.

13. Murphy, T. F., M. B. Nelson, K. C. Dudas, J. M. Mylotte, and M. A. Apicella. 1985. Identification of a specific epitope of Haemophilus influenzae on a 16,600 dalton outer membrane protein. J. Infect. Dis. 152:1300-1307.

14. Murphy, T. F., K. C. Dudas, J. M. Mylotte, and M. A. Apicella. 1983. A subtyping system for nontypable Haemophilus influenzae based on outer membrane proteins. J. Infect. Dis. 147:838-846.

15. Apicella, M. A., K. C. Dudas, A. Campagnari, P. Rice, J. M. Mylotte, and T. F. Murphy. 1985. Antigenic heterogeneity of lipid A of Haemophilus influenzae. Infect. Immun. 50:9-14.

16. Munson, R. S., Jr., and D. M. Granoff. 1985. Purification and partial characterization of outer membrane proteins P5 and P6 from Haemophilus influenzae type b. Infect. Immun. 49:544-549.

17. Murphy, T. F., and M. A. Apicella. 1985. Antigenic heterogeneity of outer membrane proteins of nontypable Haemophilus influenzae is a basis for a serotyping system. Infect. Immun. 50:15-21.

18. Gnehm, H. E., S. I. Pelton, S. Gulati, and P. A. Rice. 1985. Characterization of antigens from nontypable Haemophilus influenzae recognized by human bactericidal antibodies. Role of Haemophilus outer membrane proteins. J. Clin. Invest. 75:1645-1658.

19. Tsang, V. C. W., B. C. Wilson, and J. M. Peralta. 1983. Quantitative, single tube, kinetic-dependent enzyme-linked immunosorbent assay (K-ELISA). Methods Enzymol. 92:391-403.

20. Rice, P. A., and D. L. Kasper. 1977. Characterization of gonococcal antigens responsible for induction of bactericidal antibody in disseminated infection. J. Clin. Invest. 60:1149-1158.

21. Apicella, M. A., M. A. J. Westerink, S. A. Morse, H. Schneider, P. A. Rice, and J. McL. Griffiss. 1986. Bactericidal antibody response of normal human serum to the lipooligosaccharide of Neisseria gonorrhoeae. J. Infect. Dis. 153:520-526.

22. Anderson, P., R. B. Johnston, and D. H. Smith. 1972. Human serum activities against Haemophilus influenzae type b. J. Clin. Invest. 51:31-38.

23. Goldschneider, I., E. C. Gotschlich, and M. S. Artenstein. 1969. Human immunity to the meningococcus. II. Development of natural immunity. J. Exp. Med. 129:1327-1348.

24. Karasic R. B., C. E. Trumpp, H. E. Gnehm, P. A. Rice, and S. I. Pelton. 1985. Modification of otitis media in chinchillas rechallenged with nontypable Haemophilus influenzae and serological response to outer membrane antigens. J. Infect. Dis. 151:273-279.

25. Gigliotti, F., and R. A. Insall. 1983. Protection from infection with Haemophilus influenzae type b by monoclonal antibody to the capsule. J. Infect. Dis. 146:249-254.

26. Peltola, H., H. Kahty, and A. Sivonen. 1977. Haemophilus in- 
fluenzae type b capsular polysaccharide vaccine in children. A double blind field study of 100,000 vaccinees 3 months to 5 years of age in Finland. Pediatrics. 60:730-737.

27. Peltola, H., H. Kayhty, M. Virtanen, and P. H. Makela. 1984. Prevention of Haemophilus influenzae type b bacteremic infections with the capsular polysaccharide vaccine. $N$. Engl. J. Med. 310:1561-1566.

28. Munson, R. S., Jr., J. L. Shenep, S. J. Barenkamp, and D. M. Granoff. 1983. Purification and comparison of outer membrane protein P2 from Haemophilus influenzae type b isolates. J. Clin. Invest. 72:677684.

29. Kimura, A., P. A. Gulig, G. H. McCracken Jr., T. A. Loftus, and E. J. Hansen. 1985. A minor high-molecular-weight outer membrane protein of Haemophilus influenzae type $\mathrm{b}$ is a protective antigen. Infect. Immun. 47:253-259.

30. Myerowitz, R. L., C. W. Norden, and T. A. Demchak. 1978.
Significance of noncapsular antigens in protection against experimental Haemophilus influenzae type b disease: cross-reactivity. Infect. Immun. 21:619-626.

31. Dahlberg-Lagergard, T. 1983. Bactericidal antibodies against noncapsular components of Haemophilus influenzae. J. Clin. Microbiol. $17: 428-431$.

32. Norden, C. W., and H. A. Feldman. 1975. Haemophilus influenzae type b, antibody frequencies determined with bactericidal and radioimmunoassay tests. J. Clin. Microbiol. 2:136-138.

33. Loeb, M. R., and D. H. Smith. 1980 . Outer membrane protein composition in disease isolates of Haemophilus influenzae: pathogenic and epidemiological implications. Infect. Immun. 30:709-717.

34. Barenkamp, S. J., R. S. Munson Jr., and D. M. Granoff. 1982. Outer membrane protein and biotype analysis of pathogenic nontypable Haemophilus influenzae. Infect. Immun. 36:535-540. 